Regional Seismic Signals from Chemical Explosions, Nuclear Explosions and Earthquakes: Results from the Arizona Source Phenomenology Experiment

W. R. Walter, R. Gok, K. Mayeda, A. Sicherman, J. Bonner, M. Leidig

September 6, 2005 
This document was prepared as an account of work sponsored by an agency of the United States Government. Neither the United States Government nor the University of California nor any of their employees, makes any warranty, express or implied, or assumes any legal liability or responsibility for the accuracy, completeness, or usefulness of any information, apparatus, product, or process disclosed, or represents that its use would not infringe privately owned rights. Reference herein to any specific commercial product, process, or service by trade name, trademark, manufacturer, or otherwise, does not necessarily constitute or imply its endorsement, recommendation, or favoring by the United States Government or the University of California. The views and opinions of authors expressed herein do not necessarily state or reflect those of the United States Government or the University of California, and shall not be used for advertising or product endorsement purposes.

This work was performed under the auspices of the U.S. Department of Energy by University of California, Lawrence Livermore National Laboratory under Contract W-7405-Eng-48. 


\title{
Regional Seismic Signals from Chemical Explosions, Nuclear Explosions and Earthquakes: Results from the Arizona Source Phenomenology Experiment
}

\author{
William R. Walter ${ }^{1}$, Rengin Gok ${ }^{1}$, Kevin Mayeda ${ }^{1}$, Alan Sicherman ${ }^{1}$, \\ Jessie Bonner ${ }^{2}$ and Mark Leidig ${ }^{2}$ \\ Earth and Environmental Sciences Division, Lawrence Livermore National Laboratory ${ }^{1}$ \\ Weston Geophysics Corporation ${ }^{2}$
}

\section{Introduction}

Routine industrial mining explosions play two important roles in seismic nuclear monitoring research: (1) they are a source of background events that need to be discriminated from potential nuclear explosions; (2) as some of the only explosions occurring in the current de facto global moratoria on nuclear testing, their signals should be exploited to improve the calibration of seismic monitoring systems. A common issue arising in both of these roles is our limited physical understanding of the causes behind observed differences and similarities in the seismic signals produced by routine industrial mining blasts and small underground nuclear tests. In 2003 a consortium (Weston, SMU, LLNL, LANL and UTEP) carried out a Source Phenomenology Experiment (SPE), a series of dedicated explosions designed to improve this physical understanding, particularly as it relates to seismic methods of discriminating between signals from three different source types: earthquakes, industrial blasts, and nuclear tests. Here we very briefly review prior field experimental work that examined the seismic relationships between these source types.

The relationship between normally contained (e.g. about $120 \mathrm{~m} / \mathrm{kt}^{1 / 3}$ ) nuclear explosions and single-fired normally contained chemical explosions was studied in the 1993 NPE (Non-Proliferation Experiment). The NPE detonatated a kiloton of chemical explosive at the Nevada Test Site (NTS) in a tunnel adjacent to prior nuclear tests. The regional seismic records were found to be essentially identical, as shown in Figure 1, other than an overall chemical/nuclear yield amplitude scaling factor (e.g. Walter et al., 1994; Denny et al., 1997). Regional discriminants classified the NPE as a nuclear explosion (Walter et al., 1995). Stump et al., (1999) further demonstrated the equivalence of the two source types in the 0.36 to $100 \mathrm{~Hz}$ band using an extensive near source, free-surface instrumentation array. 


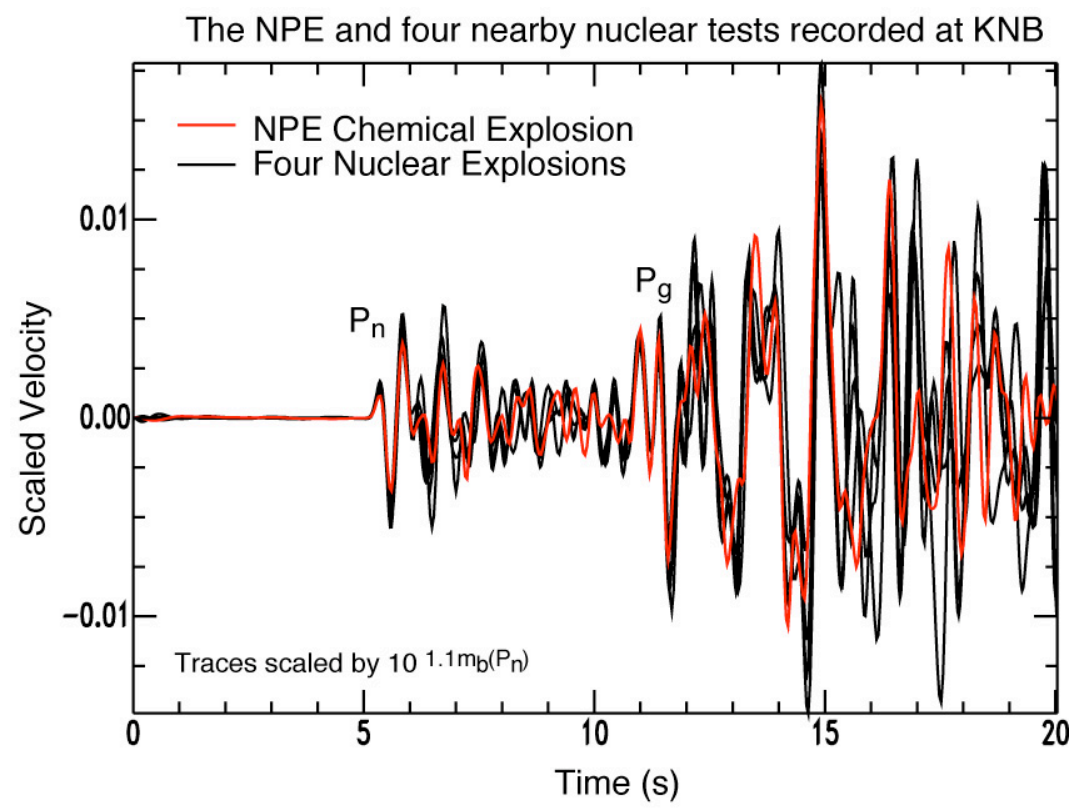

Figure 1. The NPE experiment established the seismic similarity of contained chemical and nuclear explosions. For example here we show the P waves velocity trace at KNB about $300 \mathrm{~km}$ distant compared with four nearby nuclear explosions that have been scaled by their mb values (after Walter et al. 1994).

The effect of depth on single-fired chemical explosions was examined in the 1997 Kazakhstan Depth of Burial (DOB) experiment. Shots of 25 tons were detonated at depths of $50 \mathrm{~m}, 300 \mathrm{~m}$, and $550 \mathrm{~m}$. All three shots (Figure 2) were recorded on local and regional distance stations. At local distances, the short-period Rayleigh wave $R g$ is dominant with a spectral peak at 1-3 Hz. Local $R g$ amplitude decreases markedly with increasing event depth. At regional distance, $1-3 \mathrm{~Hz} R g$ is not observed, although reflectivity synthetic seismograms predict a large $R g$ phase. However, regional $L g$ and $S n$ phases are enhanced for the shallow shots at 1-3 Hz. These observations led Myers et al. (1999) to conclude that the dominant mechanism for enhanced regional $L g$ and $S n$ excitation for the shallow shot is local $R g$ scattering. This strongly frequency dependent Rg-to S scattering mechanism would be exected to play a role in the generation of $\mathrm{S}$ waves in shallow industrial blasting as well. 


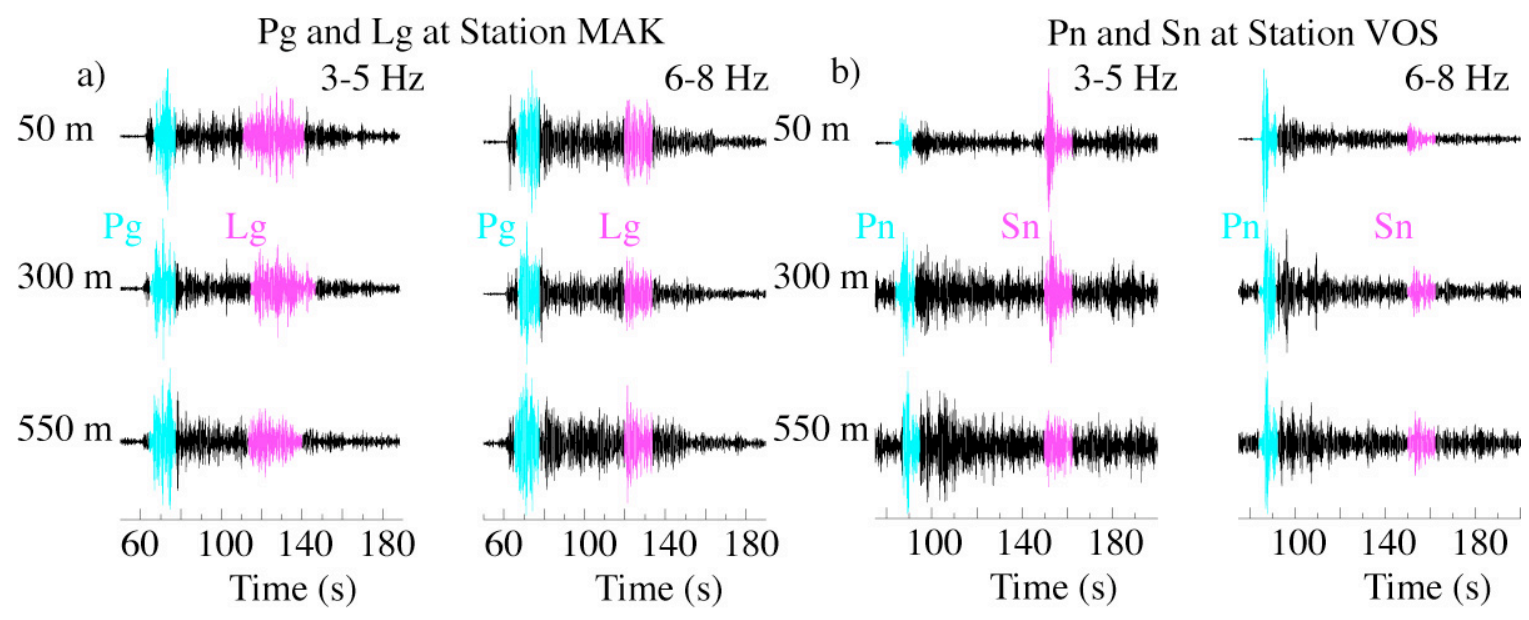

Figure 2. Regional seismograms from the 1997 Kazakhstan depth of burial experiment show the P/S ratios are a strong function of shot depth at lower frequencies (3-5 Hz) but much less so at higher frequencies (6-8 Hz). After Myers et al., 1999.

Routine mining explosions are typically made up of a number of explosive charges placed in drill holes and exploded in a sequence ("ripple-fired"), which is designed to reduce the amplitude of the of seismic signal while enhancing rock fracture and/or movement. An example would be removing the overburden above a coal seam by using explosives to "cast" the rock into a nearby pit. Another example would be the fracture of rock in place for easier removal by mechanized equipment. Thus compared to an individual nuclear or chemical explosion, industrial explosions are distributed in space and time and can involve more rock fracture and mass movement. This fracture and/or movement of rock might be expected to enhance the S-waves relative to P-waves when compared to a nuclear test. Given that high frequency $\mathrm{P} / \mathrm{S}$ is a good discriminator of nuclear tests from earthquakes, quantifying such an effect is important. Underground nuclear explosions often place a premium on containing the radioactive explosion products for safety and possibly to minimize detection of the test. Industrial explosions are usually not fully contained and thus take place at relatively shallower depths and with less vertical and horizontal overburden. As shown in the Kazakh DOB experiment this implies that Rg-to-S scattering should also play a large role in the generation of S-waves for ripple-fired blasting. However in practice it is difficult to completely separate the effects of depth, containment, fracture, media type and shooting style to really understand the nuclear test - industrial mine blast relationship.

For example the relationship between single shots and large production shots was studied at one mine, the Black Thunder coal mine in Wyoming (e.g. Stump et al., 1995; Stump and Pearson 1997; Yang et al., 1999). This mine ripple fires up to 4 kilotons of explosives at a time. Figure 3 compares two ripple-fired shots with a single-fired shot in three different frequency bands. The single-fired shot used a total of 50,000 lbs of ANFO. The ripple-fired shots were cast blasts. At low frequencies $(<1 \mathrm{~Hz})$ in the multiple shots, the amplitudes are enhanced and large surface waves are produced as shown in Figure 3. Interestingly the cast blast and single shot have some similar 
characteristics at high frequencies, despite the cast blast's design for fragmentation and rock movement. This result suggests that the enhanced rock fragmentation and mass movement of rock has little effect on relative generation of S-waves, especially compared to the strong effect of depth seen in figure 2. The Black Thunder experiments included single-fired explosions of different yields but did not investigate depth of burial and confinement effects.

\section{Black Thunder Single and Cast Shots at Pinedale $(\sim 360 \mathrm{~km})$}

- Single

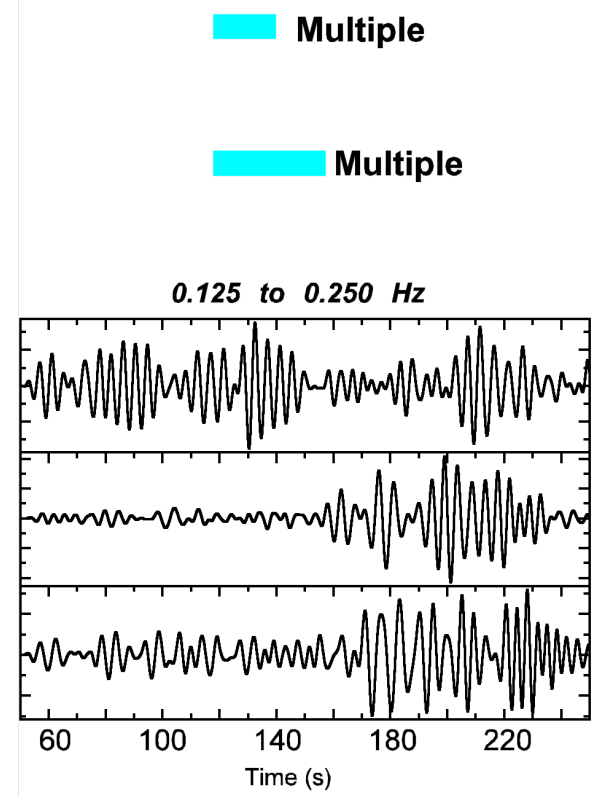

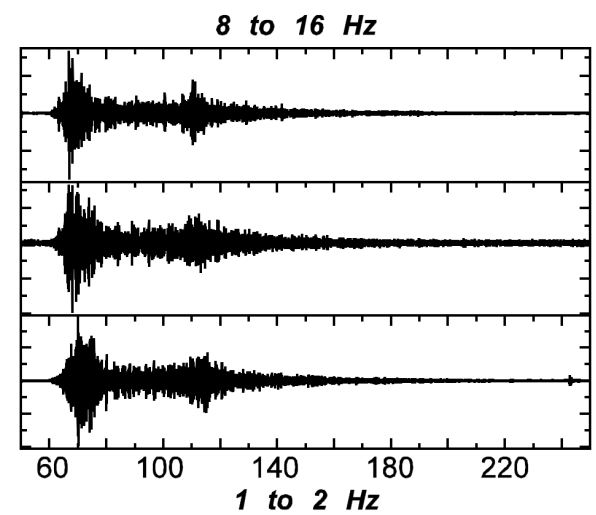
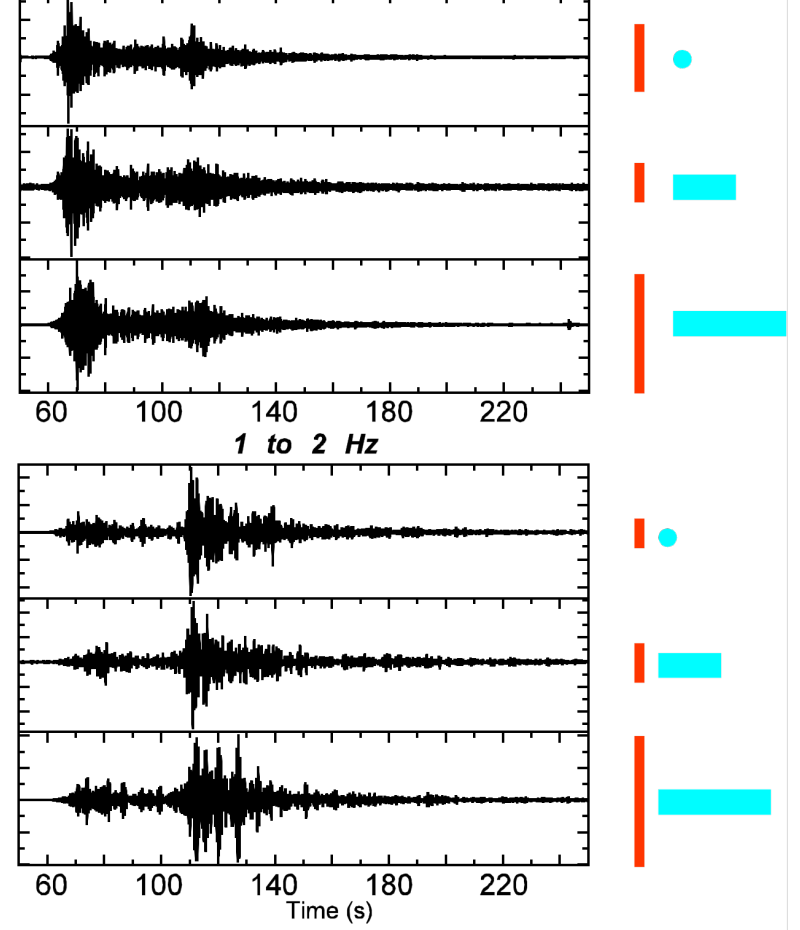

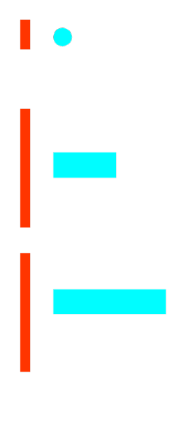

Figure 3. Comparison of single and two ripple-fired Black Thunder mine shots at a regional station. At long periods (4-8 seconds) the surface waves are enhanced as their period is long compared to the inter-shot delay times. Note the earthquake-like P/Lg values at 1-2 $\mathrm{Hz}$ and the more explosion-like P/Lg behavior at 8-16 Hz. Somewhat surprisingly above $1 \mathrm{~Hz}$ the single and multiple shots look very similar. After Stump and Pearson, 1997.

To really understand the relationship between nuclear tests and routine mine blasts would require doing nearly co-located tests of both source types to compare regional signals at common stations, however such a test is quite impractical. As an alternative a group of NNSA laboratory researchers (Walter et al. 2000) suggested using the chemical-nuclear equivalence demonstrated in the NPE to carry out a nearly colocated normally contained single-fired chemical explosion at the site of a large routine mining blasts so those signals could be compared. This idea was expended in discussions 
among a broader group in 2001-2002 to carry out a more systematic comparison of the effects of depth, containment, rock type and yield at one or more active mines. A consortium was formed by Weston, SMU, LLNL, LANL and UTEP to design such a set of experiments, carry them out, and analyze the results over the course of 2002-2005.

In this summary report on regional discriminant results from the SPE, we first briefly describe the experimental shots. Then we summarize the analysis done using regional envelope measures of seismic coda to obtain source spectra. Finally we compare the mine related events to prior nuclear tests at NTS and western U.S. earthquakes for regional body wave discrimination measures.

\section{The SPE Experiment Shots}

The western U.S. was chosen as the best location to carry out the SPE. It has abundant natural seismicity, historic nuclear explosion data, and widespread mining blasts, making it an excellent testbed to study the performance of regional seismic sourcetype discrimination techniques. The SPE experiment was carried out in Arizona at two mines that routinely produce ML $>2$ blast signals. The southern Arizona mine extracts copper and can be considered 'hardrock' geology relative to the northern Arizona mine, which extracts coal. At each mine a series of dedicated single chemical explosions was carried out at depths between 10 and $33 \mathrm{~m}$, with some in proximity to the free-face. A cartoon of the layout is shown in Figure 4. A list of the shots sizes, depths, yields and scaled yields are given in Table 1 and 2. More detail about the geology of each mine and the layout and execution of the dedicated shots can be found in the earlier chapters of this report and in Bonner et al. (2005).

\section{Source Phenomenology Experiment Schematic}

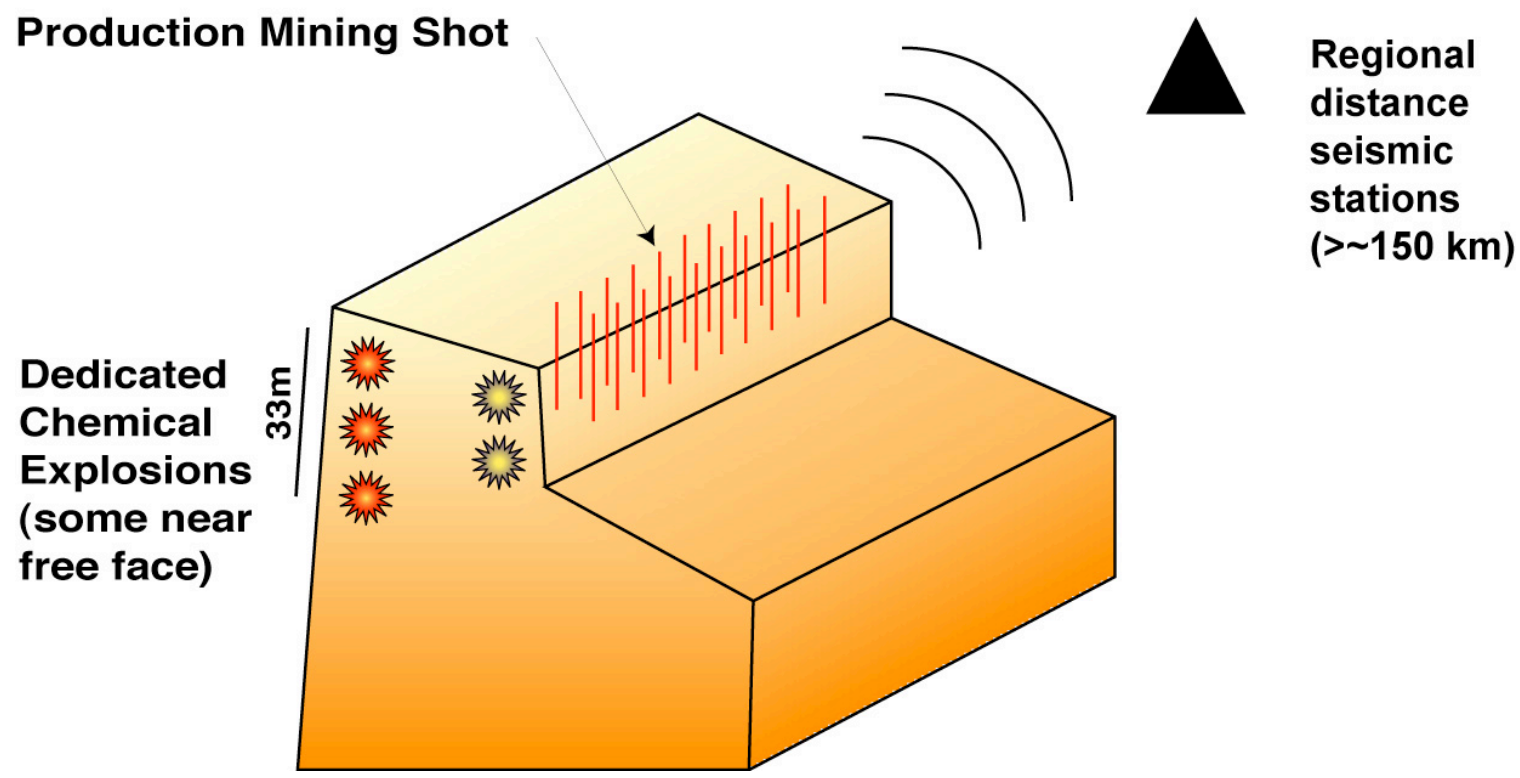


Figure 4. A cartoon view of the layout of the SPE explosions. A series of dedicated small explosions (0.1-16 tons) are carried out at a series of depth from 10-33 m, some near the free face and some well away. All are done near past or future production mining shots which are sequentially fired drill holes packed with explosives.

Table 1. Shot information for the SPE shots at a Northern Arizona mine.

\begin{tabular}{|l|l|l|l|l|l|l|}
\hline Shot & Date & Time & $\begin{array}{l}\text { Yield } \\
(\text { tons })\end{array}$ & Depth $(\mathrm{m})$ & $\begin{array}{l}\text { Scaled Depth } \\
\left(\mathrm{m} / \mathrm{kt}^{1 / 3}\right)\end{array}$ & Free Face? \\
\hline 1 & $9 / 6 / 03$ & $21: 37: 12.4$ & 16.5 & 10 & 39 & No \\
\hline 2 & $9 / 7 / 03$ & $15: 45: 48.1$ & 0.1 & 12 & 258 & No \\
\hline 3 & $9 / 7 / 03$ & $15: 57: 19.5$ & 6.0 & 30 & 165 & No \\
\hline 4 & $9 / 7 / 03$ & $16: 16: 09.5$ & 6.9 & 20 & 105 & No \\
\hline 5 & $9 / 7 / 03$ & $16: 30: 40.9$ & 4.1 & 20 & 125 & No \\
\hline 6 & $9 / 7 / 03$ & $16: 53: 26.6$ & 2.9 & 12 & 84 & No \\
\hline 7 & $9 / 7 / 03$ & $17: 17: 15.3$ & 1.8 & 12 & 99 & No \\
\hline 8 & $9 / 7 / 03$ & $17: 35: 57.6$ & 3.0 & 12 & 83 & Yes \\
\hline 9 & $9 / 7 / 03$ & $17: 47: 06.2$ & 1.6 & 12 & 103 & Yes \\
\hline
\end{tabular}

Table 2. Shot information for the SPE shots at a Southern Arizona mine.

\begin{tabular}{|l|l|l|l|l|l|l|}
\hline Shot & Date & Time & $\begin{array}{l}\text { Yield } \\
(\text { tons })\end{array}$ & Depth $(\mathrm{m})$ & $\begin{array}{l}\text { Scaled Depth } \\
\left(\mathrm{m} / \mathrm{kt}^{1 / 3}\right)\end{array}$ & Free Face? \\
\hline B1 & $8 / 18 / 03$ & $20: 18: 15$ & 0.9 & 13 & 137 & Yes \\
\hline B2 & $8 / 18 / 03$ & $20: 28: 40$ & 3.4 & 13 & 86 & Yes \\
\hline B3 & $8 / 18 / 03$ & $21: 35: 10$ & 0.9 & 13 & 137 & No \\
\hline B4 & $8 / 19 / 03$ & $18: 46: 52$ & 3.4 & 33 & 219 & No \\
\hline B5 & $8 / 19 / 03$ & $19: 04: 35$ & 3.4 & 13 & 86 & No \\
\hline B6 & $8 / 19 / 03$ & $19: 26: 03$ & 0.9 & 33 & 348 & No \\
\hline B7 & $8 / 19 / 03$ & $19: 51: 00$ & 6.8 & 13 & 69 & Yes \\
\hline B8 & $8 / 19 / 03$ & $20: 10: 39$ & 1.7 & 13 & 109 & No \\
\hline B10 & $8 / 19 / 03$ & $21: 06: 22$ & 6.8 & 33 & 174 & No \\
\hline
\end{tabular}

Shot parameters adapted from (Bonner et al., 2005). Yield is weight of ANFO rounded to nearest tenth of a ton. Shot B9 was too small to produce a regional signal and is omitted here.

\section{Coda Derived Source Spectra}

Regional coda envelopes provide very stable single station estimates of source spectra (e.g. Mayeda and Walter, 1996). We use the methodology of Mayeda et al (2003) to calibrate the paths to the regional stations KNB, TUC and ANMO using some of the few Colorado Plateau earthquakes available. The same path and site corrections are then 
applied to each event. Relative amplitudes are very well resolved and absolute amplitudes are obtained in reference to independently determined regional moments at low frequencies and the empirical Green function assumption of flat spectra at high frequencies. The earthquake displacement spectra look as expected (e.g. Brune, 1970), flat at long periods and falling off nearly with frequency as $\mathrm{f}^{-2}$ (diagonal lines shown in plots). The dedicated shots have a similar behavior and have been shown to approximately match Mueller and Murphy (1971) explosion spectra (e.g. Bonner et al., 2005). In contrast, the production shots have much stepper falloff with frequency. We believe this is a combination of enhancement of low frequency amplitude due to constructive interference of the ripple-fired explosions, and reduction at higher frequencies due to destructive interference and loss of energy to rock fracture.

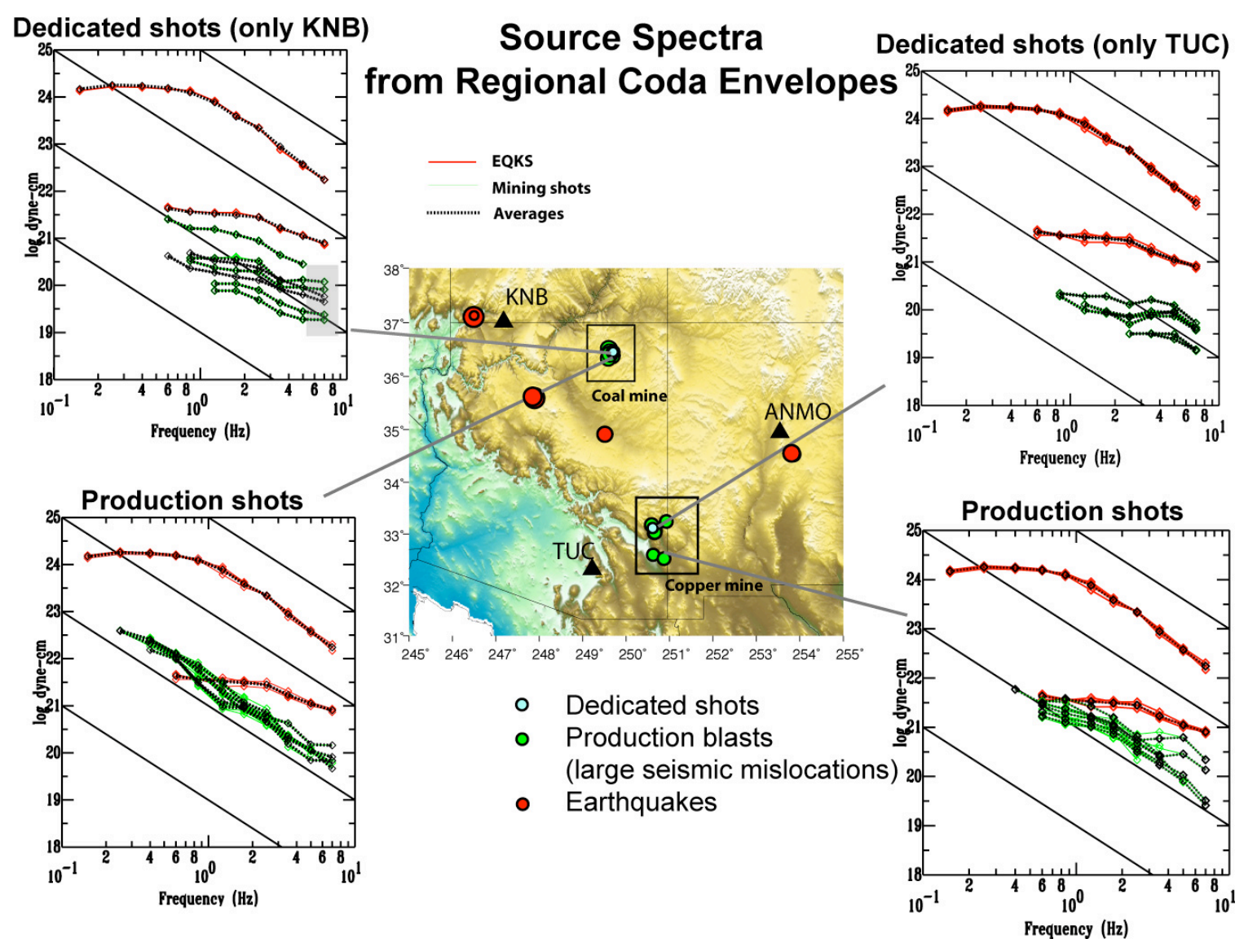

Figure 5. Regional coda envelope derived S-wave spectra of earthquakes (red) and dedicated single shot chemical explosions (light blue) and normal mine production explosions (green). The coda calibrations were done using the Colorado Plateau earthquakes shown. Left-hand side plots show the coal mine region single shots at top and ripple-fired production shots below. Similar plots for the copper mine region are shown on the right-hand side. Note that most of the ripple-fired shots have much steeper spectral falloff than the single shots. Map locations are seismic and true locations cluster tightly at each mine. 
For each station in Figure 6 we can examine the differences in the dedicated shot source spectra as determined from the coda. The differences in source spectral shape due to depth and confinement are quite subtle. One slight difference is seen between shots 3 and 4 at the northern coal mine, which are similar size but slightly different true and scale depths. The deeper shot 3 has more relative energy at high frequencies $(>1 \mathrm{~Hz})$ as might be expected due to a smaller elastic radius and higher corner frequency. Shot 8 in comparison is about half the yield of shots 3 and 4 but has a similar level below $1 \mathrm{~Hz}$ perhaps related to its even shallower depth and larger expected elastic radius. Shot 8 is also has less high frequency energy which may be partly due to its proximity to the free face in addition to the expected lower corner frequency. A fuller analysis is planned for the future to compare these regional results with the local much broader bandwidth data, the moment tensor results and the video data.
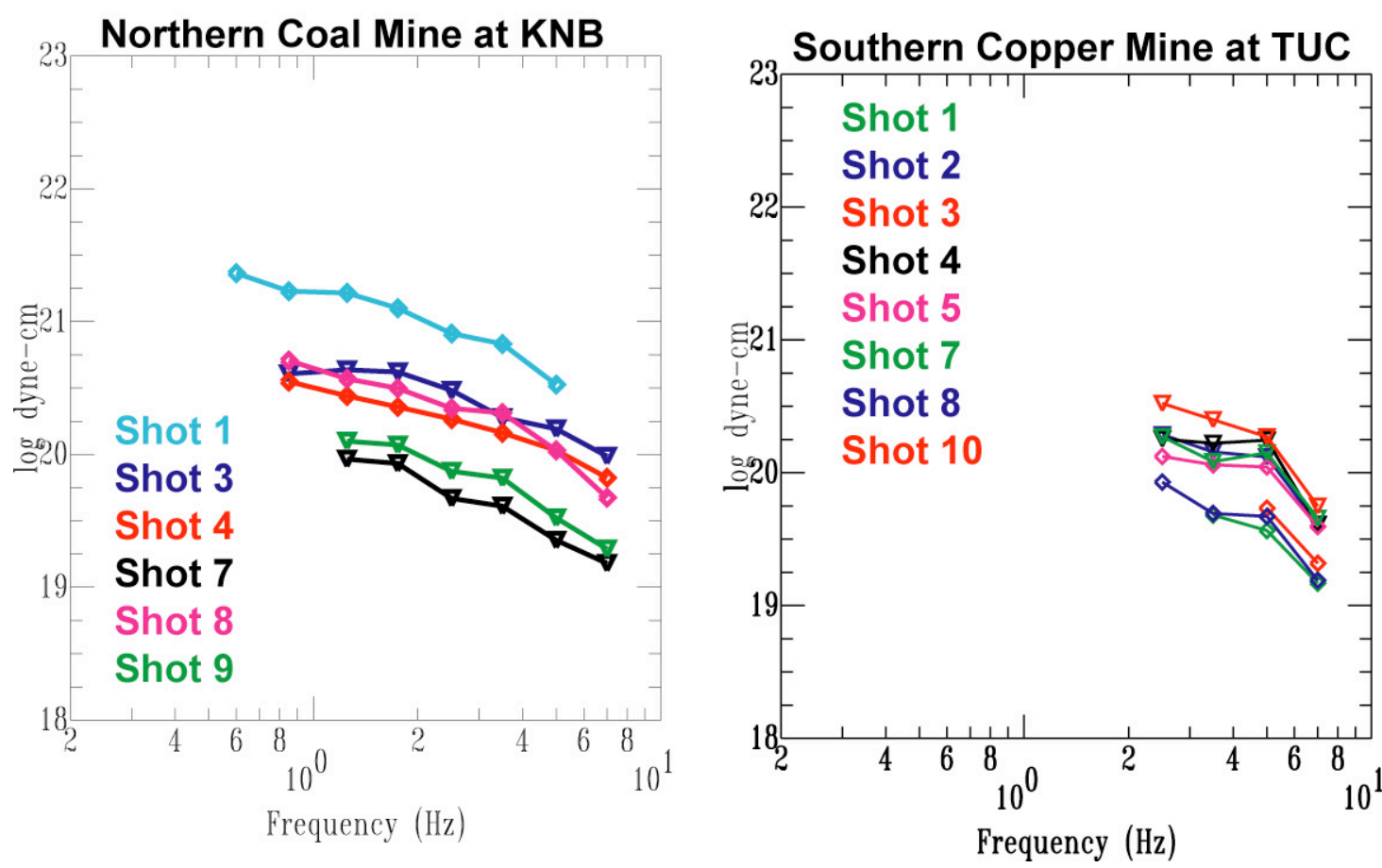

Figure 6. Coda derived source spectra of dedicated shots using the closest regional station for each of the two mines.

Another interesting effect is shown in Figure 7. Between the two types of mine the Copper mine shows less 6-8 Hz energy than the Coal mine. This is clear in the comparison of similar size ( 6 and 6.8 tons) and depth $(30$ and $33 \mathrm{~m})$ events. This may be related to the media difference between the hard rock Copper and softer rock coal mine. This difference causes the Copper mine to have larger low/high spectral ratios than the Coal mine when we examine discriminants in the next section. Again the regional results need to be compared to local data for a full analysis. 


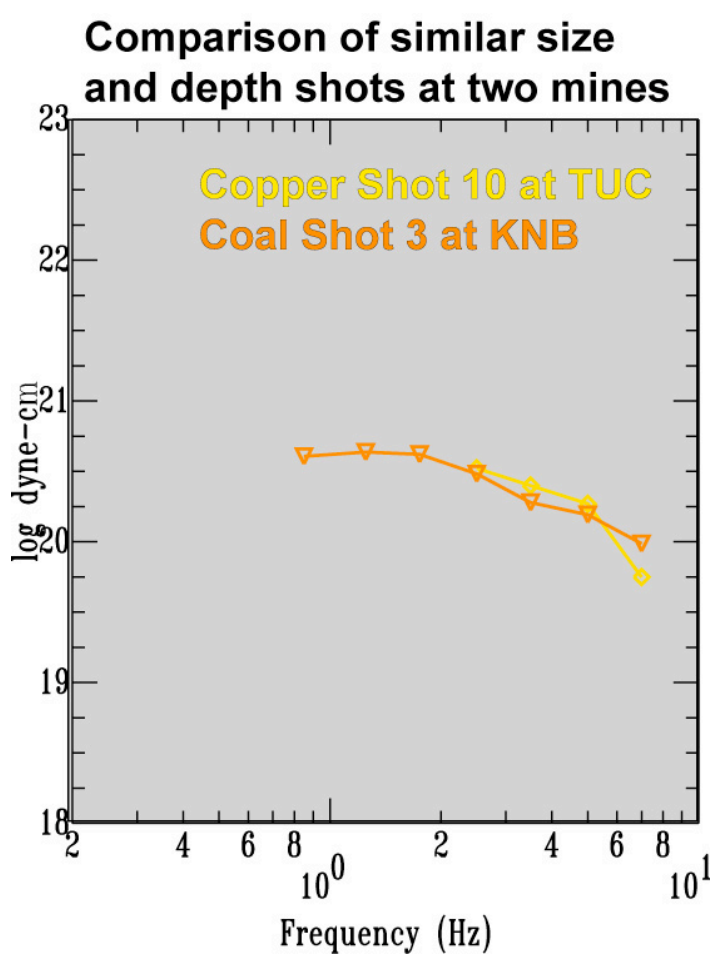

Figure 7. A comparison of two similar yield and depth shots at the two different mines. Interestingly the shot in the harder rock copper mine has less energy at 6-8 Hz than the softer rock coal mine shot.

\section{Regional Phase Discrimination}

\section{Data}

One reason for conducting the SPE in the western U.S. is to be able to compare with the large database of underground nuclear tests, earthquakes and industrial mine explosions which we assembled under a prior year BAA (Walter et al. 2003). The western U.S. nuclear explosion data covers a wide range of depths and material properties and has excellent ground truth information (Springer et al. 2002). This is unlike the situation in most of the world where regional recordings of nuclear tests are scarce and discrimination optimization needs to be done in their absence. We show in Figure 8 the location of regional events and stations that we have analyzed for this report.

Effective earthquake-explosion discrimination has been demonstrated in a broad variety of studies using ratios of regional amplitudes in high-frequency (primarily 1-to 20-Hz) bands (e.g. Walter et al., 1995, Taylor, 1996, Hartse et al. 1997, Rodgers and Walter, 2002, Taylor et al., 2002, Battone et al. 2002 and many others). When similar-sized earthquakes and explosions are nearly co-located, we can understand the observed seismic contrasts, such as the relative P-to-S wave excitation, in terms of depth, material property, focal mechanism and source time function differences. However, it is well known that path propagation effects (e.g. attenuation, blockage) and source scaling 
effects (e.g. corner frequency scaling with magnitude) can make earthquakes look like explosions and vice versa. We have developed a technique called MDAC (Magnitude and Distance Amplitude Corrections, Walter and Taylor, 2002) that can account for these effects with proper calibration. We use the earthquakes alone to determine the MDAC parameters such as geometrical spreading, frequency dependent $\mathrm{Q}$ and the average apparent stress.

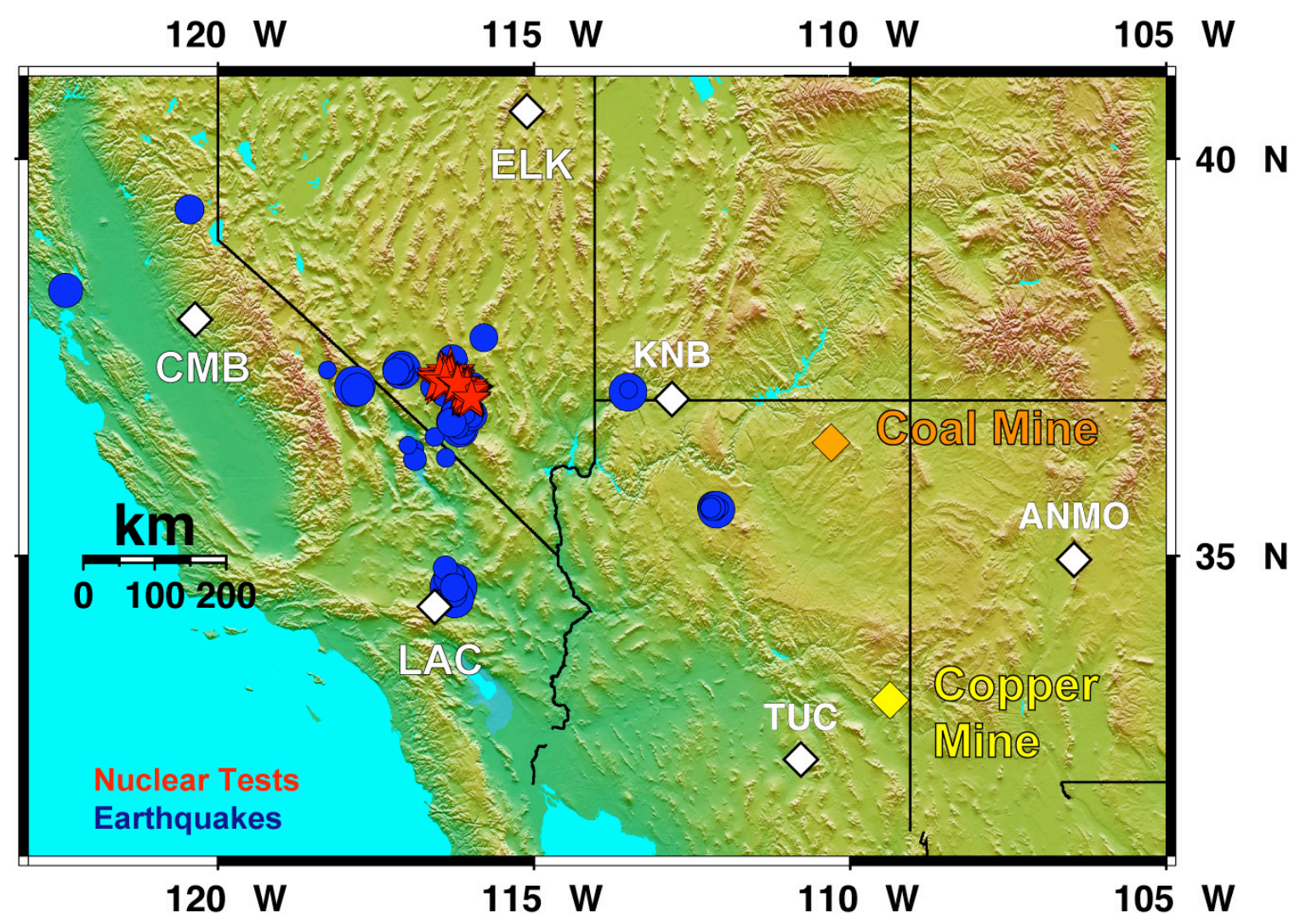

Figure 8. Topographic map showing the locations of historic nuclear explosions (red stars), earthquakes (blue circles), Arizona SPE mines (orange and yellow diamonds) and seismic stations (white diamonds) used in this report.

\section{MDAC based path corrections}

The MDAC formulation assumes the observed, instrument correct spectra $O(f)$ are given by a combination of a source model, $S(f)$, a geometrical spreading factor $G(R)$ depending on the distance $\mathrm{R}$ and an apparent attenuation factor $\mathrm{A}(\mathrm{f}, \mathrm{R})$ :

$$
O(f)=S(f) G(R) A(f, R)
$$

The source model is a generalized Brune type spectrum (see Walter and Taylor, 2002). The geometrical spreading term follows Street et al. (1975) to define a critical distance $\mathrm{R}_{\mathrm{o}}$ 
within which the spreading is spherical and beyond which it decays as distance to the power $\eta$ :

$$
G\left(R \geq R_{o}\right)=\frac{1}{R_{o}}\left(\frac{R_{o}}{R}\right)^{\eta}
$$

Here we used $R_{o}$ of $100 \mathrm{~km}$ for the crustal phases Pg and Lg. For the apparent attenuation we us a standard frequency dependent formulation:

$$
A(f, R)=\exp \left(-\frac{\pi f R}{Q(f) c}\right)
$$

Where $\mathrm{c}$ is the velocity of the phase and $\mathrm{Q}(\mathrm{f})$ is the quality factor, which has frequency dependence of the form:

$$
Q(f)=Q_{o} f^{\gamma}
$$

Here we fix the source and geometrical spreading terms and perform a grid search for the best fitting $\mathrm{Q}_{\mathrm{o}}$ and gamma parameters as shown in Figure 9.

\section{Pg Attenuation Grid Search}

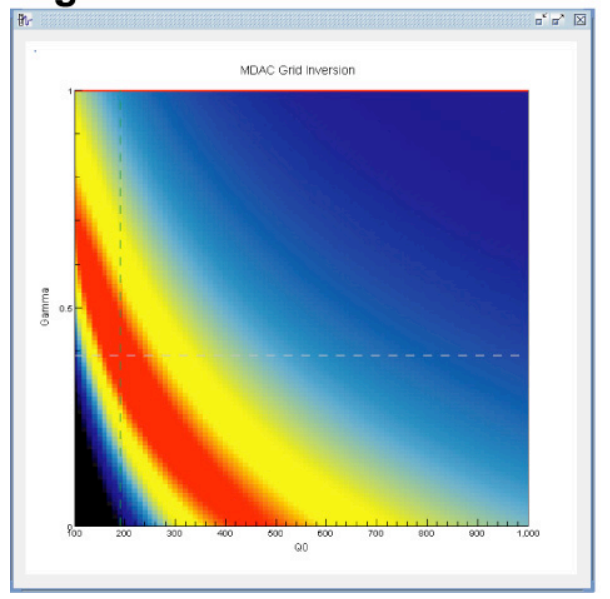

\section{Lg Attenuation Grid Search}

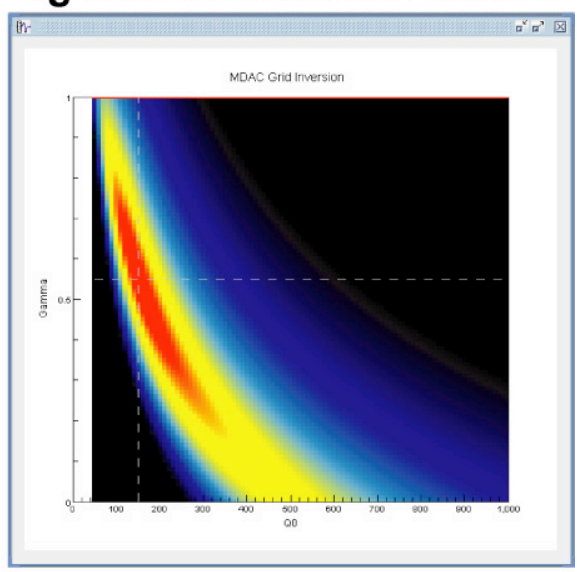

Figure 9. Grid search results for the best Qo (x-axis) and gamma (y-axis) attenuation parameters for $P g$ and $L g$. These results are based on minimizing the spectral misfit in 8 frequency bands from $0.5-8 \mathrm{~Hz}$ simultaneously. Misfit shown in color from best results in red to worst in blue-black. Lg results are better resolved than Pg but there is some tradoff between the two attenuation parameters for both phases.

After calibration the MDAC formulation provides expected spectral amplitudes as a function of phase, magnitude and distance. These can then be subtracted from the actual observations. For earthquakes the corrected data should exhibit a close zero mean, and no significant trends with magnitude and distance. In practice, because we are minimizing misfit to all frequencies simultaneously, there can be small residual trends, but the overall scatter or range of residuals is greatly reduced, thereby improving 
discrimination. Explosions should have significant non-zero mean residuals, also leading to improved discrimination. We show the results of a low to high frequency Lg spectral ratio before and after MDAC correction in Figure 10.

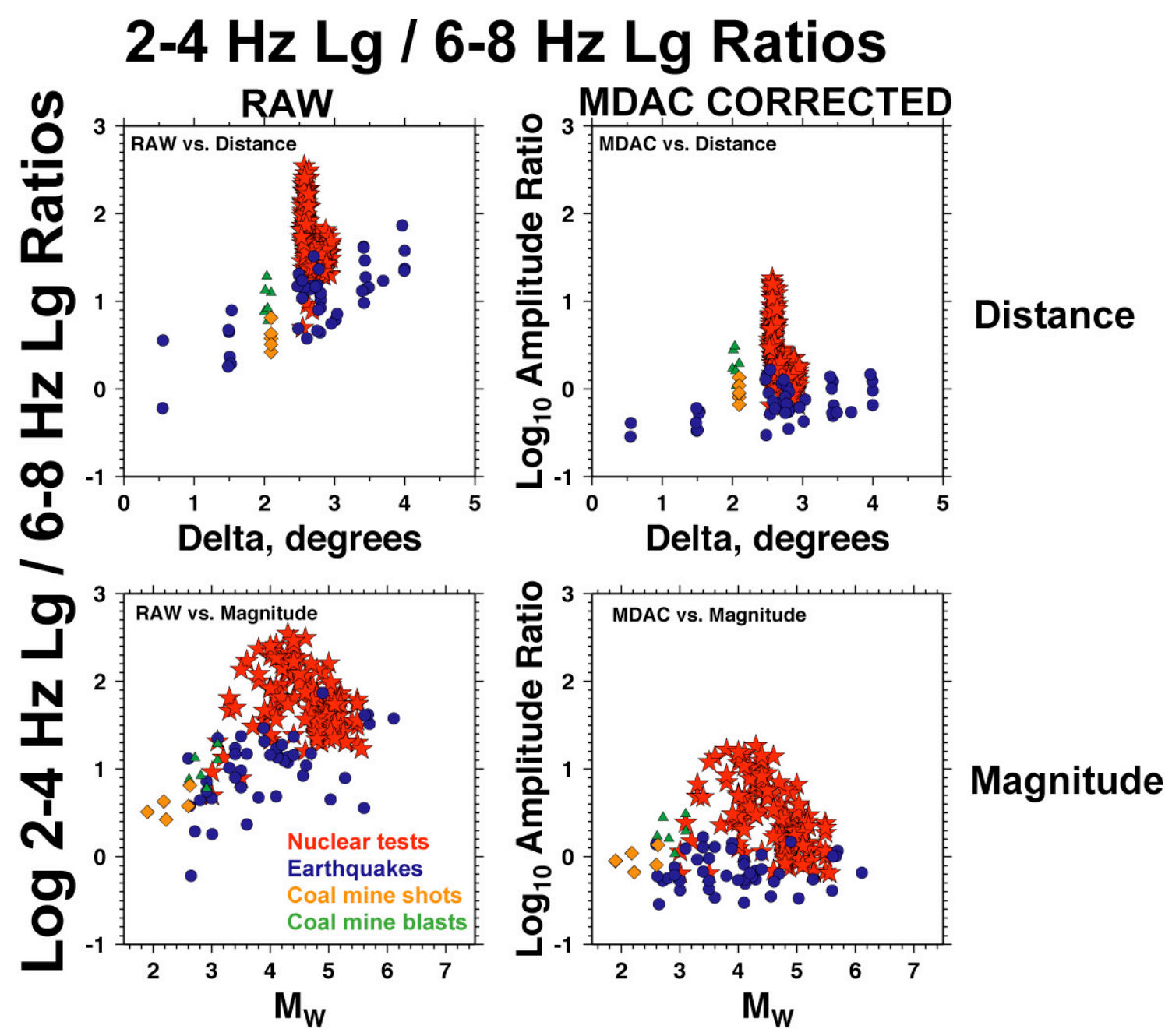

Figure 10. Western U.S earthquakes (blue circles), nuclear explosions (red stars), northern Arizona coal mine dedicated shots (orange diamonds) and regular production mine blasts (green triangles) for the discriminant ratio of (2-4 Hz Lg) / (6-8 Hz Lg) at station $K N B$. The left-hand side shows raw data as a function of distance (top) and magnitude (bottom). The right-hand side shows MDAC corrected data. Note that strong distance and magnitude trends apparent in the raw data are removed by MDAC, improving discrimination.

\section{Discrimination Results}

After the MDAC correction we can explore the performance of the different possible ratios of amplitudes. We can also find optimal combinations of particular regional discriminants (e.g. Taylor 1996). We use the linear discriminant analysis method (LDA) to find the optimal coefficients to combine the measurements. As an example 
of this we show in figure 11 a combination at KNB of three different regional phase and spectral ratios.

\section{Optimized Multivariate Discrimination at KNB}
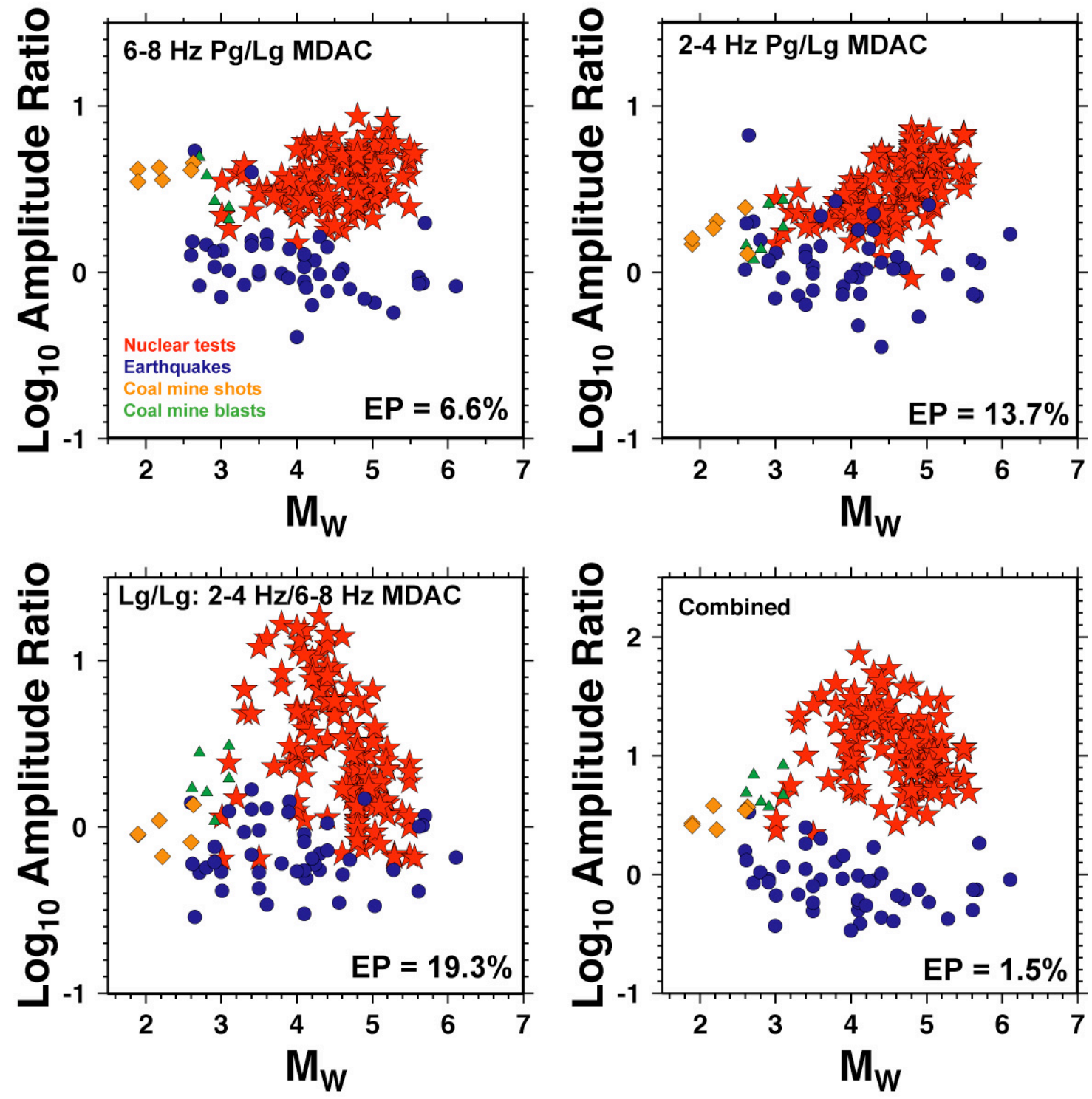

Figure 11. We show nuclear explosion discrimination from earthquakse at station $K N B$ for 3 different regional phase ratios after MDAC corrections were applied. In the lower right we combine these 3 ratios using an optimal set of weights determined using LDA to get a dramatic increase in performance. The combination is 0.71 (6$8 \mathrm{~Hz} \mathrm{Pg/Lg})+0.88(2-4 \mathrm{~Hz} \mathrm{Pg} / \mathrm{Lg})+0.57(2-4 / 6-8 \mathrm{~Hz} \mathrm{Lg/Lg})$. This shows how optimally combining even mediocre discriminants can improve performance of very good discriminants because new information always helps. Note the mine shots track the nuclear tests for the P/S ratios but not the low to high Lg ratio. Using the mine shots to obtain LDA weights would degrade the nuclear explosion discrimination performance. 
The metric of performance we use is the equiprobable point (EP), which provides a measure of the overlap of the earthquake and explosion populations. It is the point on a receiver operating characteristic (ROC) tradeoff curve where the error rates are equal. For example an equiprobable point of 0.1 implies that $10 \%$ of the earthquakes are misclassified as explosions and $10 \%$ of explosions are misclassified as earthquakes. In practice one might chose a decision line with unequal error rates, such as by picking a low probability of misclassifying an explosion. The equiprobable point provides a single numerical measure of performance that is much more intuitive than other measures such as Mahalanobis distance, though it can be formally related to that measure under particular assumptions.

A very interesting result demonstrated in Figure 11 is that by adding together several different mediocre discriminant measures using LDA coefficients we can greatly improve performance. In fact using LDA we can always improve performance by adding another discriminant measure because it provides new information. In practice we have found that after combining about 3 to 5 different regional amplitude ratios using LDA, further improvement by adding additional measures is limited, as the extra measures do not provide much new information.

The $\mathrm{P} / \mathrm{S}$ ratios in Figure 11 show that the dedicated shots have similar values to the nuclear explosions at both 2-4 and 6-8 Hz. We expect this for the shots that are well contained based on our NPE and Kazakh DOB experience. As expected, the scatter at $2-4 \mathrm{~Hz}$ is slightly larger than at 6-8 Hz, which we expect based on our Kazakh DOB experience to be due to the depth variation effect on Rg generation, as this has a larger effect at lower frequencies (see figure 2). We can clearly see the same effect when we compare the Coal mine shots 1 and 3 in Figure 12. These shots at $10 \mathrm{~m}$ and $33 \mathrm{~m}$ respectively, have the greatest range of depth in this experiment. The shallower shot clearly has larger Lg amplitudes relative to Pg at 2-4 Hz when compared to the deeper shot. This effect goes away at 6-8 Hz. The same effect as was observed in the Kazakh DOB results (compare with Figure 2) although here it is a bit subtler as the depth range is much less. This implies that depth has a large effect on $\mathrm{P} / \mathrm{S}$ ratios for frequencies below about $5 \mathrm{~Hz}$ and little effect at higher frequencies. This appears to be more support for the Rg scattering hypothesis as the major contributor to low frequency explosion S waves (e.g. Myers et al., 1999). 

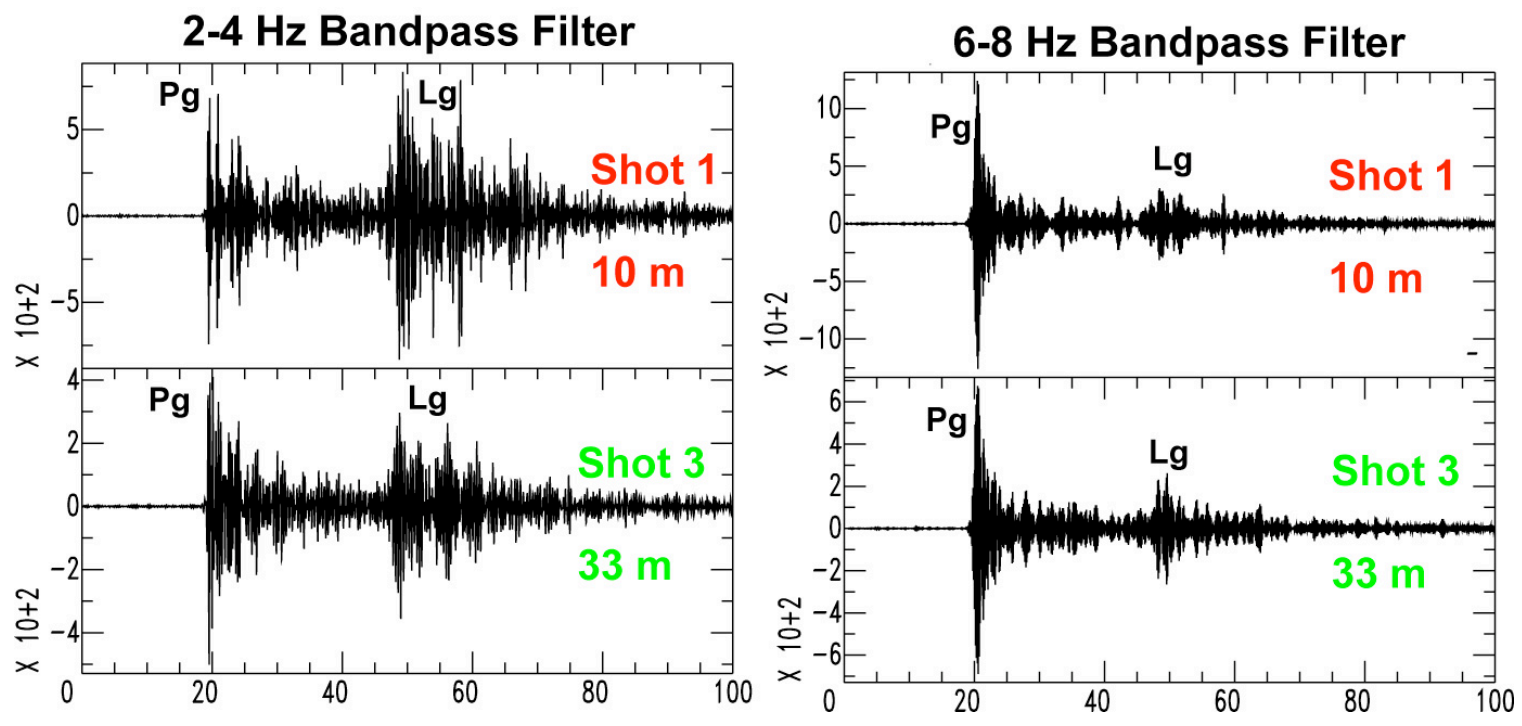

Figure 12. Comparison of shallow and deep Coal mine shots in two frequency bands. Compare with figure 2. There is a clear depth effect difference above and below about $5 \mathrm{~Hz}$ with the shallow shot having more Lg energy relative to Pg at the lower frequencies.

For the low to high frequency spectral ratio discriminants (2-4 Hz Lg / 6-8 Hz Lg) the production shots are systematically higher than the dedicated shots. This is also clearly apparent in the coda spectra where the production shot amplitude drops off more rapidly with frequency (see figure 5). Some of this is due to the change from purely coherent to purely incoherent summation of energy as we span the frequency range with respect to the interference of the ripple-fired explosion. There may also be an effect due to rock fracture and movement but to model this we need to do further comparison with the local and video data.

We performed similar analysis for the southern copper mine shots at station TUC as shown in figure 13. At station TUC we see similar behavior of the Copper mine SPE shots as was observed at KNB for the Coal mine shots except the frequency content difference between shots and production blasts as observed in $\mathrm{Lg} / \mathrm{Lg}$ low high frequency ratio is even larger. At ANMO we can see shots from both mines, but due to strong attenuation and limited data availability in years prior to 1992 we are not able to observe high frequency regional phases from nuclear tests at stations TUC and ANMO. 

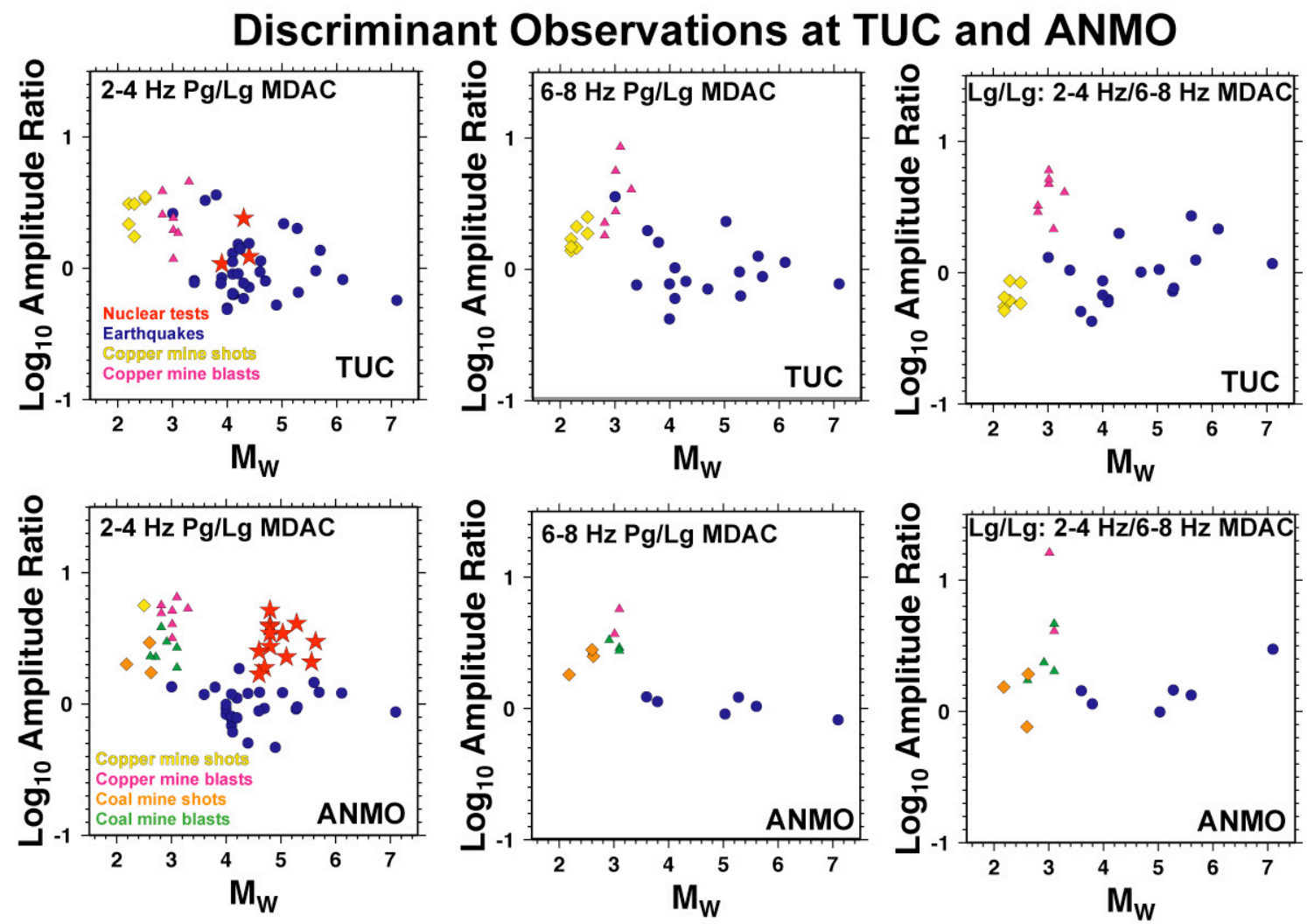

Figure 13. MDAC corrected regional phase discrimination ratios compared to historic nuclear tests and earthquakes. Top row shows results at TUC for the Copper mine and bottom row shows results for both mines at ANMO.

\section{Comparison of the Two Mines}

One interesting difference we observe between the southern hardrock copper mine and the northern coal mine is a significant difference in relative $\mathrm{Pg} / \mathrm{Lg}$ content as shown in the 2-4 Hz ANMO seismograms in Figure 14. One might think this could be the result of unmodeled path differences, but we examined these same shots at some the stations along the temporary line of stations deployed by UTEP and observed similar differences. At $2-4 \mathrm{~Hz}$ for similar depth and yield shots, the hardrock copper mine has less Lg energy relative to Pg than the northern coal mines. It seems possible that the strongly different velocity models and fracture behavior of the rock at the two mines may contribute to this difference. If $\mathrm{Rg}$ scattering is a significant contributor to $\mathrm{Lg}$ at 2-4 $\mathrm{Hz}$ at the coal mine then it does not seem to be as strong an effect at the copper mine. Some possible explanations for this would be that in the faster velocity material the Rg peak spectral amplitude is shifted to higher frequencies relative to the coal mine case. The faster material may also have lower attenuation so that Rg may propagate to relatively larger distances as a distinct phase. The Rg must scatter relatively early into S-wave energy to be included in the Lg window; late scattered 
energy would appear in the coda. As a follow-on study we want to compare the coda spectra with the Lg spectra for these two events.

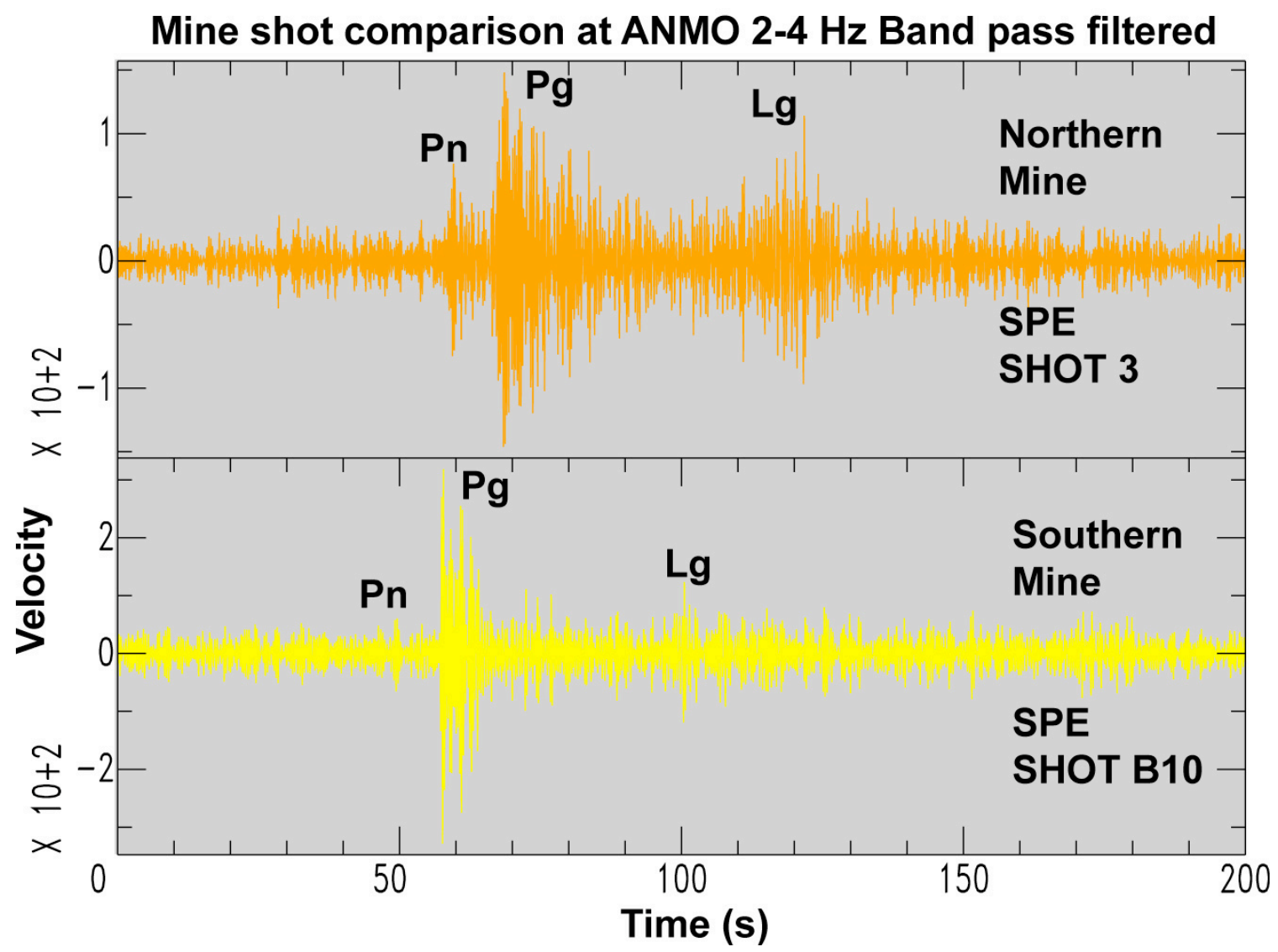

Figure 14. A comparison of similar size (6.0 and 6.8 tons) and depth shots (30 and $33 \mathrm{~m}$ ) from the two different mines recorded at the same station ANMO. Despite being farther away the northern mine shot shows clearer Pn and Lg amplitudes. The significant difference in Pg energy relative to Lg is also observed at some of the temporary stations deployed between the two mines.

We note that the copper mine shots do show a similar effect with depth of burial as the coal mine shots at 2-4 Hz. For example we compare copper mine shot B5 (3.4 tons at 13 $\mathrm{m}$ depth) with shot B4 (3.4 tons at $33 \mathrm{~m}$ depth) at station TUC in Figure 15. At lower frequencies, like $2-4 \mathrm{~Hz}$, there is a clear difference in relative $\mathrm{Pg} / \mathrm{Lg}$ values with depth. However the copper mine seismograms show much less variation in relative $\mathrm{Pg} / \mathrm{Lg}$ than the coal mine, and as seen in Figure 15, the 6-8 Hz Pg/Lg values are very similar to the 2$4 \mathrm{~Hz}$ values. This is in stark contrast to the coal mine shots observed at KNB and shown in Figure 12. 

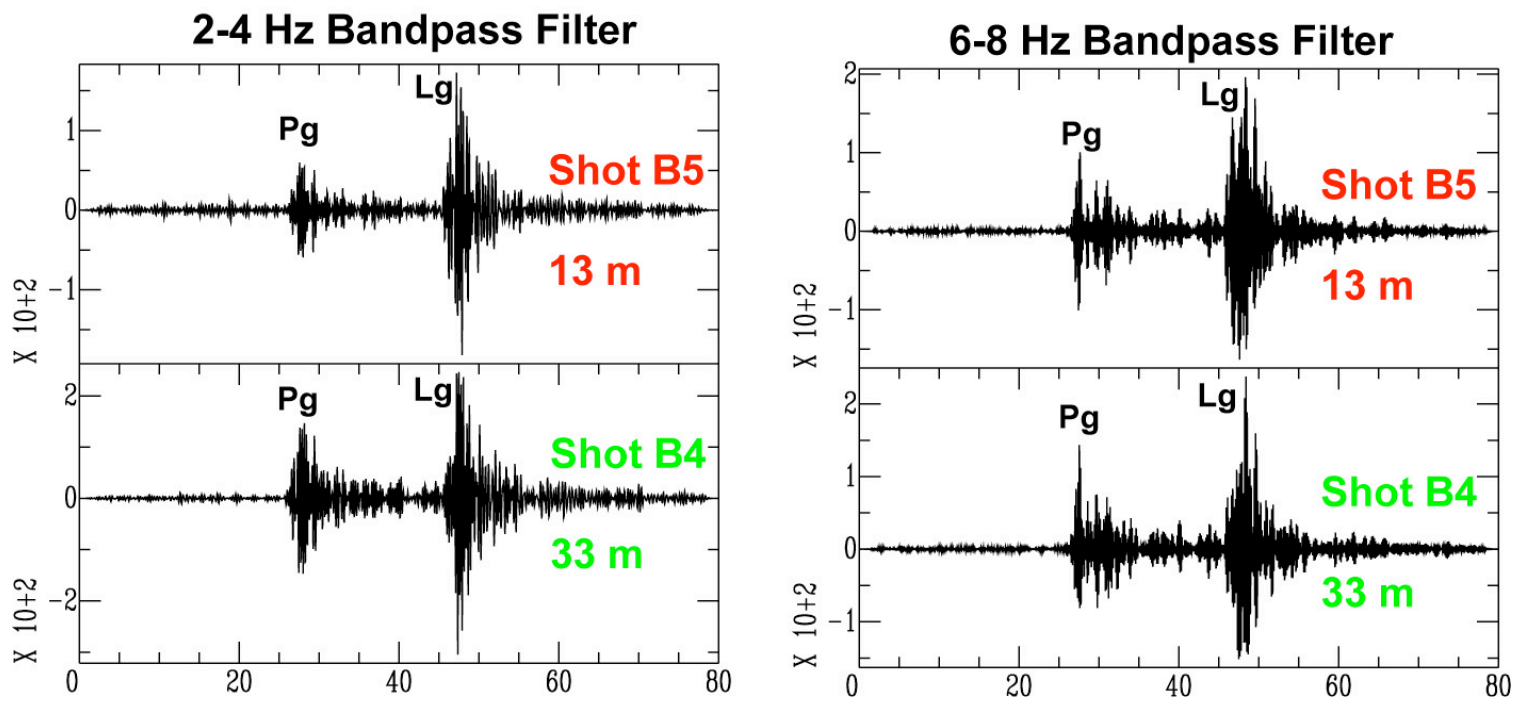

Figure 15. Comparison of similar size shallow and deep Copper mine shots in two frequency bands. Compare with figure 12 and figure 2. There is a clear depth effect difference at 2-4 $\mathrm{Hz}$ with the shallow shot having more Lg energy relative to $\mathrm{Pg}$. However compared to the coal shots at KNB shown in figure 12 there is much less change in $\mathrm{Pg} / \mathrm{Lg}$ values as you move to high frequency.

To summarize the behavior of the relative $\mathrm{P} / \mathrm{S}$ amplitudes observed from the dedicated shots, we show in Figure 16 the $6-8 \mathrm{~Hz}$ and $2-4 \mathrm{~Hz}$ values as a function of depth of burial (DOB) and scaled depth of burial (SDOB). In this plot we have removed the free face shots (shots 8, 9, B1, B2 and B7) and kept only measurements with a signal-to-pre-eventnoise level of 2 or more. Here we can see the clear split in $\mathrm{P} / \mathrm{S}$ depth dependent behavior at about $5 \mathrm{~Hz}$ for the coal mine, which does not seem to be the case for the copper mine. These results make an interesting dataset for the Rg scattering hypothesis to fit. If this hypothesis is correct then the velocity, attenuation and scattering differences between the two mines should be able to explain the observed differences. In addition we should see significant differences in frequency content and amplitude decay of the direct Rg phase observed in the local data. This will be an area of future work. 

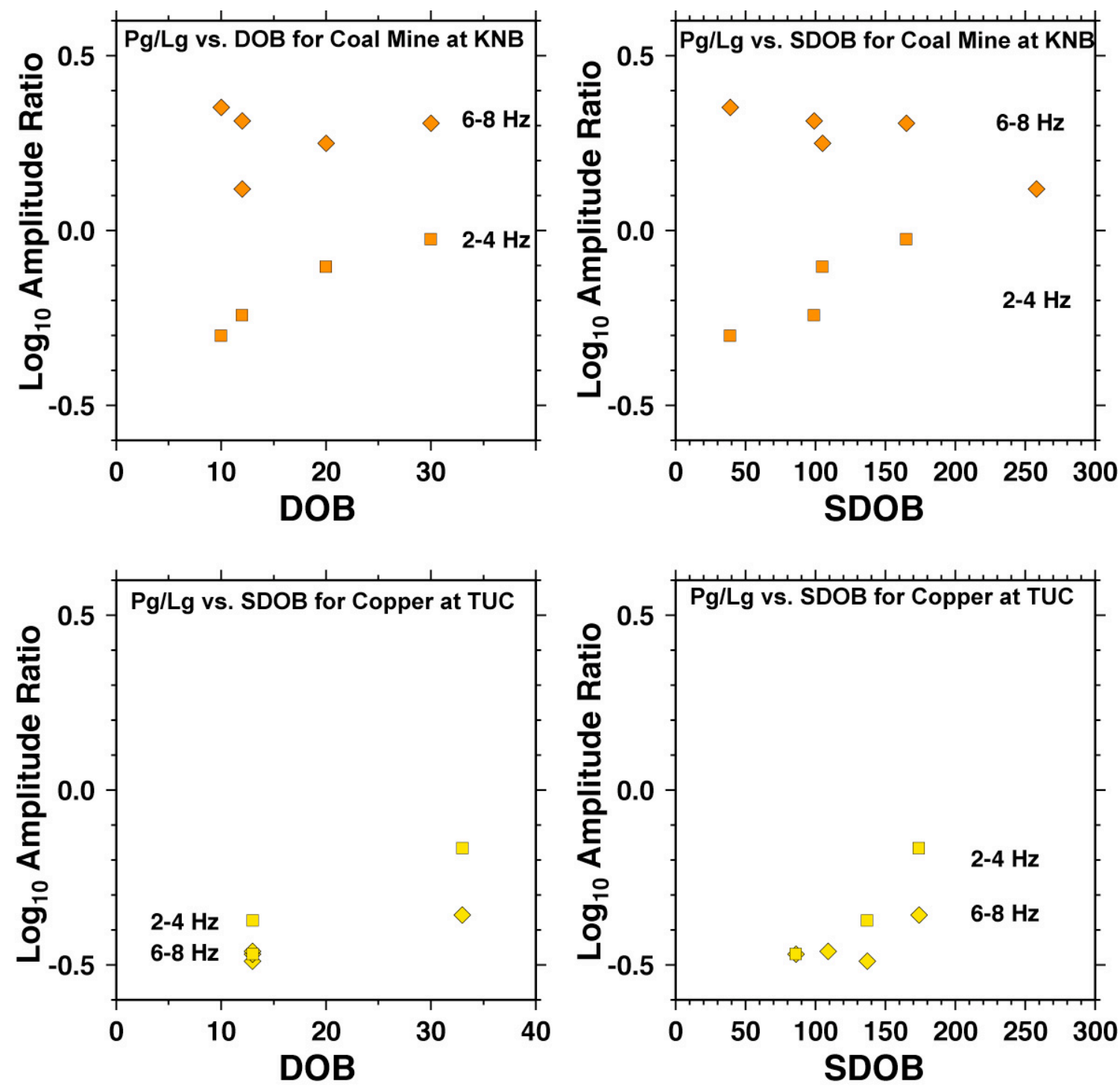

Figure 16. Comparison of the non-free-face dedicated mine shot Pg/Lg values in two frequency bands versus depth of burial (DOB) and scaled depth of burial (SDOB). The 2-4 Hz values are shown as squares and the 6-8 Hz values as diamonds. The coal mine points are on top in orange and the copper mine points are at the bottom in yellow. The 2-4 $\mathrm{Hz}$ coal mine Pg/Lg values show clear trends with DOB and SDOB while the 6-8 Hz values do not. For the copper mine the $\mathrm{Pg} / \mathrm{Lg}$ values are similar for the two frequency bands and both show some scaling with DOB and SDOB.

\section{Effects of the Free-Face}

Finally we briefly examine the effect of explosions near the free face, where significant material is horizontally displaced into a pit. In Figure 17 we compare two similar size and depth shots (3.4 tons at $13 \mathrm{~m}$ ) recorded at TUC, where one is located close to a free face and the other is not. The figure shows, somewhat unexpectedly, that the free face 
shot has larger Pg relative to $\mathrm{Lg}$ at $2-4 \mathrm{~Hz}$ and 6-8 Hz. Again the $\mathrm{Pg} / \mathrm{Lg}$ ratio shows only small changes as we move up in frequency between 2 and $8 \mathrm{~Hz}$ as compared to the coal mine shots.
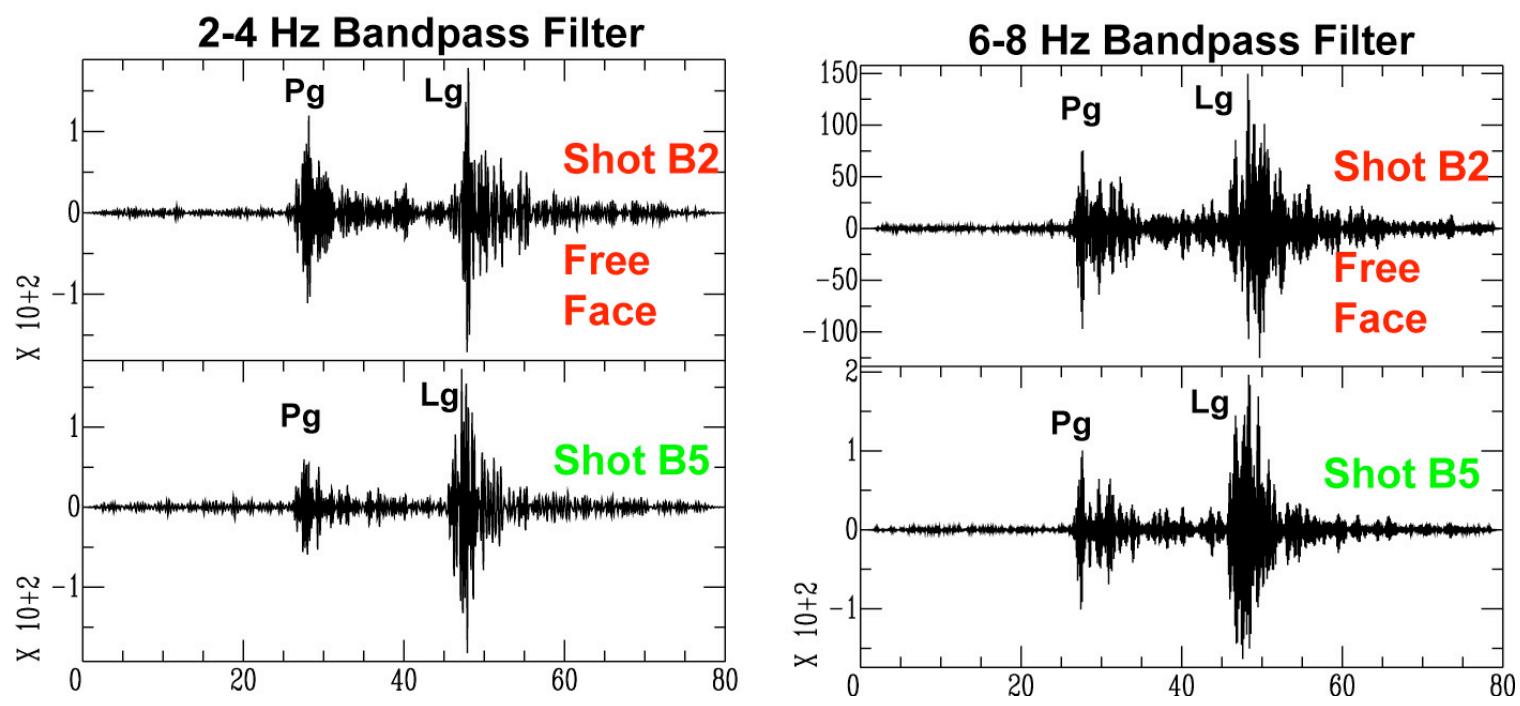

Figure 17. Comparison of free face effect for the same depth and yield shots at the copper mine. The free face shot has more Pg energy relative to $\mathrm{Lg}$, especially at the lower frequencies as recorded here at station TUC.

The free face shots may have significant azimuthal variation with the orientation of the free face relative to the station, so some caution must be used in looking at TUC alone. We also looked at these same shots as recorded at some of the temporary stations deployed along the line between the mines. We see similar behavior; the free face shot $\mathrm{B} 2$ has higher $\mathrm{Pg} / \mathrm{Lg}$ values than B5. However these northern stations show larger $\mathrm{Pg} / \mathrm{Lg}$ values (relatively more Pg, less Lg than at TUC) consistent with likely azimuthal effects and therefore these results should be compared with the more azimuthally complete local data.

\section{Conclusions}

- The SPE single-fired normally contained shots have similar P/S values to nuclear tests, as expected from our NPE experience.

- The production shots also have similar $\mathrm{P} / \mathrm{S}$ ratios to the nuclear tests but show a larger scatter then the dedicated shots, indicating that the production shot variability is coming from more than depth and confinement effects.

- The SPE shots show only very subtle differences in relative spectral content at regional distance due to depth and confinement, based on regional S-wave coda envelopes. 
Perhaps this because most of the observations are below the source corner frequencies where the main effect is an overall moment level change and differences in the Green's function for $1-8 \mathrm{~Hz}$ regional phases appear small.

- The SPE single-fired shots at the softrock mine have less $2-4 \mathrm{~Hz}$ energy relative to 6-8 $\mathrm{Hz}$ energy than the production shots at the same mines (smaller spectral ratios).

- At frequencies of 2-4 Hz the regional $\mathrm{Pg} / \mathrm{Lg}$ ratios appear to be a function of depth and consistent with the Rg scattering hypothesis which also fit the Kazakh DOB results (e.g. Myers et al. 1999).

- The frequency dependent behavior of the $\mathrm{P} / \mathrm{S}$ ratios appears to vary with emplacement media, as reflected by the different behavior of the softrock coal mine when compared with the hardrock copper mine as one moves up in frequency from $2-4 \mathrm{~Hz}$ to 6-8 $\mathrm{Hz}$.

- For regions without nuclear test data it appears that mine blasts can be used to test $\mathrm{P} / \mathrm{S}$ discriminants, but because the spectral content shows large variation with mine type (hard versus soft rock) and shooting style (single versus ripple fired, near free-face or not), that makes it harder to use for surrogate nuclear test calibration when the shooting layout is unknown.

- More analysis is needed to better tie these regional results to the results using the local data.

Acknowledgements. We gratefully acknowledge the efforts of all of the SPE consortium participants and the staff at each of the mines that made this project a success. We thank Ms. Veronica Parker who picked some of the TUC and ANMO data while a summer student at LLNL in 2004. We thank Stan Ruppert, Terri Hauk and Jennifer O'Boyle for loading and maintaining the LLNL database. This work was performed under the auspices of the U.S. Department of Energy by the University of California, Lawrence Livermore under contracts No. W-7405-Eng-48. This is LLNL contribution UCRL ??????

\section{References}

Battone, S., M. D. Fisk and G. D. McCarter (2002), Regional Seismic-Event Characterization Using a Bayesian Formulation of Simple Kriging, Bull. Seism. Soc. Am., 92, pp. 2277-2296.

Bonner, J. L., B. Stump, M. Leidig, R. Zhou, T. S. Kim, W. R. Walter, A. Velasco, C. Hayward, D. Baker, C.L. Edwards, S. Harder, H. Hooper, T. Glenn, C. Zeiler, J. Britton, X. Yang, J. F. Lewkowicz, W. S. Blomberg, B. Greschke, S. Azevedo, and G. Gettamy (2005). Preliminary Report on source Phenomenology Experiments in Arizona, (in prep). 
Denny, M. D., editor, 1994. Proceedings of the Symposium, The Non-Proliferation Experiment (NPE): Results and Inplications for Test Ban Treaties, Dept. of Energy, CONF-94-04100, April 1994.

Denny, M. D., P. G. Goldstein, K. Mayeda, and W. R. Walter, (1997), Seismic results from DOE's Non-Proliferation Experiment: A comparison of chemical and nuclear explosions", In Monitoring a Comprehensive Test Ban Treaty, edited by E. S. Husebye and A. M. Dainty 355-364, Kluwer Academic Publishers.

Hartse, H., S. R. Taylor, W. S. Phillips, and G. E. Randall (1997). A preliminary study of regional seismic discrimination in Central Asia with an emphasis on Western China, Bull. Seism. Soc. Am. 87, 551-568.

Mayeda, K. M. and W. R. Walter, (1996). Moment, energy, stress drop and source spectra of Western U.S. earthquakes from regional coda envelopes, J. Geophys. Res., 101, 11,195-11,208.

Mayeda, K., A. Hofstetter, J. L. O'Boyle and W. R. Walter (2003). Stable and transportable regional coda magnitudes based on coda-derived moment rate spectra, Bull. Seism. Soc. Am. 93, 224-239.

Myers, S. C., W. R. Walter, K. M. Mayeda, and L. Glenn, (1999), Observations in support of $R g$ scattering as a source for explosion $\mathrm{S}$ waves: regional and local recordings of the 1997 Kazakhstan depth of burial experiment, Bull Seism. Soc. Am., 89, 544-549.

Rodgers, A. J. and W. R. Walter, (2002). Seismic Discrimination of the May 11, 1998 Indian Nuclear Test with Short-Period Regional Data From Station NIL (Nilore, Pakistan), Pure Appl. Geophys. 159, 679-700.

Springer, D. L., G. A. Pawlowski, J. L. Ricca, R. F. Rohrer and D. K. Smith, (2002). Seismic source summary for all U.S. below-surface nuclear explosions, Bull. Seism. Soc. Am. 92, 1806-

Street, R. L., R. Herrmann, and O. Nuttli (1975). Spectral characteristics of the Lg wave generated by central United States earthquakes, Geophys. J. R. Astron. Soc. 41, 51-63.

Stump, B.W., D.C. Pearson, R.L. Martin, P.E. Harben, C.L. Edwards, D. Baker, K. Kihara, K. Dalrymple, J.P. Lewis, D. Rock, and R. Boyd, (1995), The Black Thunder regional seismic experiment, 10 June - 19 September 1995, Los Alamos National Laboratory, Los Alamos, NM, LA-UR-95-3980.

Stump, B.W., and D.C. Pearson, (1997), Comparison of single-fired and delay-fired explosions at regional and local distances, Proceedings of the $19^{\text {th }}$ Annual Seismic Research Symposium on Monitoring a Comprehensive Test Ban Treaty.

Stump, B.W., D.C. Pearson, and R.E. Reinke, 1999. Source comparisons between nuclear and chemical explosions detonated at Rainier Mesa, Nevada Test Site, Bull. Seism. Soc. Am., 89, 409-422.

Taylor, S., (1996). Analysis of high-frequency Pg/Lg ratios from NTS explosions and Western U.S. earthquakes, Bull. Seism. Soc. Am., 86, 1042-1053.

Taylor, S., A. Velasco, H. Hartse, W. S. Philips, W. R. Walter, and A. Rodgers, (2002). Amplitude corrections for regional discrimination, Pure. App. Geophys. 159, 623650.

Walter, W. R., K. Mayeda and H. J. Patton, (1994). Regional seismic observations of the non-proliferation experiment at the Livermore NTS network, in The Non- 
Proliferation Experiment (NPE): Results and Inplications for Test Ban Treaties, edited by M. Denny, 6-193 - 6-201, Dept. of Energy, CONF-94-04100, April 1994.

Walter, W. R., K. Mayeda, and H. J. Patton, (1995). Phase and spectral ratio discrimination between NTS earthquakes and explosions Part 1: Empirical observations, Bull. Seism. Soc. Am., 85., 1050-1067.

Walter, W. R., M. Denny, S. Myers and C. Pearson, (2000). A mining/contained explosion source phenomenology experiment to improve nuclear test monitoring, Lawrence Livermore National Laboratory Report, UCRL-ID-138079, January 2000.

Walter, W. R. and S. R. Taylor (2002), A revised Magnitude and Distance Amplitude Correction (MDAC2) procedure for regional seismic discriminants, Lawrence Livermore National Laboratory UCRL-ID-146882.

Walter, W. R., K. D. Smith, J. L. O'Boyle, T. F. Hauk, F. Ryall, S. D. Ruppert, S. C. Myers, M. Anderson, and D. A. Dodge (2003). Improving the fundamental understanding of regional seismic signals with a unique western United States dataset, in "Proceedings of the $25^{\text {th }}$ annual Seismic Research Review".

Yang, X., B. Stump and D. C. Pearson, (1999). Moment Tensor Inversion of Single-hole Mining Cast Blast, Geophys. J. Int., 139, 679. 